\title{
La población judeoconversa de Ocaña (Toledo) a principios del siglo XVI
}

\author{
Gonzalo Viñuales Ferreiro*
}

\section{RESUMEN ABSTRACT}

En 1537 había en la villa de Ocaña

(Toledo) más de doscientos judeoconversos, según se deduce de un censo realizado por el obispo de Calahorra. Ya en 1497 fueron habilitados sesenta y nueve vecinos, después de haber sido relajadas y reconciliadas más de cien personas desde 1485. Dedicados principalmente al sector secundario, muchos judeoconversos conservaron sus prácticas y costumbres mosaicas, manteniendo los lazos familiares, aunque a lo largo del siglo XV aumentaron los casos de bautizados convencidos que trataron de integrarse paulatinamente en la sociedad cristiana.
There were more than two hundred judeo-converts in 1537 in the village of Ocaña (Toledo), according to a tax made by the bishop of Calahorra. In 1497 hardly seventy neighbours were qualified, after were ruptured and reconcilied more than one hundred people since 1485. They were dedicated principaly to the second sector, many judeo-convers kept their mosaic practices and customs, manteinig the family ties, although during the fifteen century grew the cases of baptizied that tried to integrate slowly in the christian society.

Auto de fe, sambenito, limpieza de sangre, tortura, judeoconversos, Inquisición. Palabras que han fascinado a los estudiosos, a los investigadores, a los curiosos. Sobre ello se han escrito y publicado infinidad de páginas, desde monografías de conjunto, diccionarios, o cuadernos divulgativos hasta historias locales, biografías de inquisidores o procesos particulares. De

* Becario. M.E.C. (UNED). 
una concepción sensacionalista que consideraba al Santo Oficio como un instrumento más del poder real, que empleaba métodos terribles en sus procesos, se ha ido pasando a una interpretación mucho más exhaustiva y científica, aclarando las interpretaciones, ofreciendo estadísticas precisas y profundizando en historias concretas que aclaren la perspectiva general.

En este marco se ubica este artículo de historia local, que pretende dibujar un panorama de la realidad de la población judía que se había bautizado en la villa toledana de Ocaña, a partir de la documentación inquisitorial. Partiendo de una bibliografía bastante específica ${ }^{1}$, hemos examinado detenidamente los procesos que se conservan en el Archivo Histórico Nacional referidos a vecinos de Ocaña. Entre los expedientes de inhabilitación hay una Relación de los linajes no limpios de Ocaña que fizo el obispo de Calahorra, compuesto por varios pliegos donde este obispo anotaba diversas notas tomadas de los libros de testificaciones de la Inquisición de Toledo, entre las que se encuentra un censo de los cristianos nuevos de esta localidad ya fueren descendientes de moros o de judíos ${ }^{2}$.

\section{EL PASADO JUDIOO DE OCAÑA}

De 1296 data el primer testimonio documental que prueba la presencia de población hebrea en la villa toledana de Ocaña. El rey Fernando IV ordenaba que todos los vecinos de Ocaña satisficieran las deudas contraídas con la aljama judía, y regulaba cómo habían de dirimirse las querellas que los semitas presentasen ante el concejo.

La aljama de Ocaña no aparecía en el repartimiento de Huete de 1290, pues había pechado junto con la de Toledo, como demuestra el hecho de que en 1313, ya rey Alfonso XI, se conceda al maestre de la Orden de Santiago, Diego Moñiz, el pecho que debían al monarca los judíos de esta localidad.

Para mejor asegurar su defensa y repoblación, la villa de Ocaña había sido entregada a la Orden de Santiago en 1182, quien detentará su dominio a lo largo de toda la Edad Media. Según La Primera Crónica General y

1 Cantera, F. y León, P: Judaizantes del arzobispado de Toledo habilitados por la Iriquisición en 1495 y 1497. Madrid. 1969; BLÁZQUEZ, J: la Inquisición en Castilla-La Mancha. Madrid. 1986; CaRRasco, R: «Solidaridades judeoconversas y sociedad local» en Inquisición y Conversos. III Curso de cultura hispano-judia y sefardí. Toledo. 1994; PARELLO, V: Les judéo-convers. Tolède XVe-XVle siècles. De l'exclusion à l'intégration. París. 1999.

2 Archivo Histórico Nacional. (en adelante, A.H.N. ).Inquisición. (en adelante, INQ). Leg. 120. Exp. 39. 
el arzobispo de Toledo, Jiménez de Rada, Ocaña había pasado a manos cristianas como parte de la dote que Zaida, hija del rey de Sevilla, Aben Habet, diera al rey Alfonso VI. Más probable se antoja el hecho de que cayera con motivo de la toma de Toledo, y que su control residiera en las tropas cristianas de Alvar Fañez ${ }^{3}$.

Sin embargo, las campañas de los almorávides privaron a los castellanos de su dominio, quienes habrían de esperar a 1139 para recuperar definitivamente el control de Ocaña, gracias a la toma de Oreja y su comarca. Como muestra del poco interés que despertaba Ocaña, Alfonso VII no organizó su repoblación hasta 1156, año en el que le otorgó el fuero de Oreja. Su sucesor, Alfonso VIl, descubrió la relevancia estratégica de la villa de Ocaña, y la puso en manos de los magnates castellanos Pedro Gutiérrez y Tello Pérez, quienes entre 1174 y 1181 la cedieron a la Orden de Calatrava, que al año siguiente la entregó a la de Santiago a cambio de una renta anual ${ }^{4}$.

Durante el siglo XIV la minoría judía se fue consolidando en Ocaña. Las dificultades de la convivencia se manifiestaron en los pleitos continuados entre judíos y cristianos acerca de las deudas judiegas, sobre lo que ya había ordenado Fernando IV y cuyas disposiciones seguían aún sin cumplirse. Sin embargo, entre ellos se observan también intercambios económicos, pues se venden y compran tierras y casas, apareciendo algunos judíos que desempeñan cargos de prestigio, como Don Abrahem Abzaradiel, recaudador en el arciprestazgo de La Guardia, y que moraba en Ocaña.

La primera mención a la realidad económica de la comunidad hebrea de Ocaña se nos ofrece más nítida en 1386. Juan de Aponte pagaba cuatro mil maravedíes por el juro de heredad que tenía sobre el pecho de la aljama de los judíos de Ocaña, y el castillo y villa de Monreal.

La aljama judía de Ocaña no se libró de las revueltas antijudías de 1391 y fue saqueada, según testimonio del historiador judío Selomoh ben Verga en su Sébet Yehudá. Carecemos de noticias alusivas a los hebreos de Ocaña para el primer tercio del siglo $\mathrm{xV}$, pero el montante económico con el que contribuye Ocaña en el impuesto de la «cabeza de pecho" de 1439 , casi diez mil maravedíes, y la continua referencia a judíos de Ocaña como arrendadores de impuestos de la catedral de Toledo, nos permiten suponer que el pogrom de 1391 no sólo no afectó gravemente a la comunidad semita de Ocaña sino que ésta salió fortalecida gracias a la llegada de población judía de otras aljamas más castigadas.

\footnotetext{
GonzÁlez, Julio: Repoblación de Castilla La Nueva. Madrid. 1975. vol. I. págs. 90-91. Idem, págs. 264-266.
} 
La importancia de la aljama de Ocaña fue aumentando progresivamente a lo largo del siglo xv. En 1491, vísperas de la expulsión, la comunidad semita de Ocaña, junto con las de Yepes, Santa Cruz, La Guardia, Colmenar de Oreja, Lillo y Corral de Almaguer, fue la tercera que más pagó de toda la Corona de Castilla, en el servicio de los castellanos de oro. Y según se desprende del estudio de los padrones fiscales referidos al «servicio y medio servicio», y de los restantes pagos de los castellanos de oro, la comunidad hebrea de Ocaña solamente fue superada entre 1474 y 1490 por las aljamas de Toledo, que pagaba junto con Gálvez, Alcázar de Consuegra, Ventas con Peña Aguilera y Torrijos; la de Guadalajara, a la que se unían las de Valdeyunques, Atazo, Málaga, Malaguilla, Valdeniruelo y Loeches, la de Segovia, acompañada por la de Turégano; y la de Trujillo que tributó con Jaraicejo y Montánchez.

José Luis Lacave explica este consirable protagonismo como consecuencia de la expulsión de los judíos de Sevilla, Córdoba y Cádiz decretada en 1483 por los Reyes Católicos, obligando a muchos judíos a salir de estas tierras, buscando refugio en localidades de menor presencia judia, donde las condiciones de acogida fueran más favorables. Dentro de este contingente de personas destacó Yehudah ibn Verga, matemático, astrónomo y cabalista sevillano, posible pariente del citado historiador Selomoh ben Verga, defensor de los judíos de Jerez de la Frontera ante el Duque de Medina Sidonia, acusados de enterrar en su cementerio a un converso, y que aparece en Ocaña entre 1487 y 1491 como arrendador de tributos de la catedral de Toledo ${ }^{5}$. En Ocaña encontramos también al conocido rabino Ishaq de León, amigo personal de Alfonso de Caballería, y que tenía instalada allí su academia, síntoma de la vitalidad de la comunidad hebrea de esta villa ${ }^{6}$.

Sin embargo, el año record fue 1485 , a partir del cual se observa un descenso brusco en la cantidad aportada debido probablemente al establecimiento de la Inquisición en Toledo, y al aumento de las conversiones. Con todo, en torno a 1492 se estima una población judía para Ocaña en torno a las mil quinientas personas, demostrando que esta aljama mantuvo su gran importancia hasta el final.

En su libro, Juderías y sinagogas españolas, José Luis Lacave sitúa el barrio judío en torno a la iglesia de San Juan, cuya nave principal la tradición ha considerado parte de la antigua sinagoga, basándose en las referencias

Sáenz-Badillos, Ángel: Literatura hebrea en la España Medieval. Madrid 1991. pág. 250.

BAER, Yitzhak: Historia de los judios en la España Cristiana. 1998. Barcelona. $(1945,1959)$. pág. 808 . 
documentales que ofrece Pilar León en su obra, Judíos de Toledo, pues se menciona a un judío, Yuçé Çarfatí, como morador en la colación de Santa María, calle Chamorro, nombre que se ha mantenido hasta la actualidad. Por otro lado, en el proceso de la Inquisición contra Alfonso Núñez de Sevilla se menciona al reo como vecino de la calle de San Juan.

Sin embargo, parece más probable que la población hebrea estuviera repartida por toda la villa, en virtud del número de judíos que allí habitaban y por algún testimonio documental que sitúa a judíos viviendo en la calle Frías, y en la calle Mayor. Además, en las listas de conversos de 1537 se distribuye a esta población en dos grupos, los de Santa María, y los de San Pedro, lo que demuestra una posible mayor amplitud espacial de la judería. Otro argumento favorable a esta interpretación se desprende de la lectura del mencionado proceso inquisitorial, ya que el preso, Alfonso Núñez, afirma no saber a qué sinagoga conducía el aceite, lo que permite suponer que habría más de una.

Aunque no gozamos de certeza documental, existe el convencimiento de que el cementerio de los judíos de Ocaña se hallaba en las afueras de la villa, en el cerro conocido como el Mazacote, debido a algunos testimonio orales que afirman haberse encontrado posibles lápidas judias en excavaciones que allí se realizaron. Asunto que no pierde nunca su carácter de hipótesis.

Por último, sabemos gracias a la documentación inquisitorial que en Ocaña los judíos tenían carnicería propia donde sacrificar a los animales siguiendo el ceremonial impuesto por el Talmud, que convierte a la carne en khaser, o alimento apto para su consumo.

\section{LA POBLACIÓN JUDEOCONVERSA DE OCAÑA Y LA INQUISICIÓN}

Procesado por judaizante entre 1487 y 1490 , Ruy González, escribano, afirma ser el primer cristiano nuevo de judío que se convirtió en Ocaña, en tiempos de Fray Bicente ${ }^{7}$. Este dato aislado certifica el pobre efecto de las violencias antijudías de 1391 en Ocaña, pues no aparece población conversa hasta veinte años más tarde, y casi de una manera anecdótica.

Blanca Díaz declara en su proceso en 1486 que «[...] hace treinta años que se quitó de las ceremonias de la ley de Moisés [...]" ${ }^{8}$, siendo ésta la

A.H.N. INQ. Leg. 155. Exp. 16. Es posible que se refiera a las predicaciones de San Vicente Ferrer, a comienzos del siglo XV.

8 A.H.N. INQ. Leg. 141. Exp. 13. 
única noticia conservada sobre judeoconversos vecinos de esta villa toledana hasta la irrupción en escena de la Inquisición en Toledo en 1485 procedente de Ciudad Real. Comenzaba una persecución sin tregua contra el criptojudío.

El santo Oficio seguía un procedimiento de actuación concreto. La Inquisición había nacido para asegurar que la conversión de los nuevos bautizados era sincera, y su primer objetivo era reconducir a aquellos que mantenían, aún después de convertidos, la fe en la ley de Moisés. A éstos se les ofrecía la posibilidad de confesar sus culpas y ser reconciliados con la Iglesia a cambio de alguna penitencia, en un perícdo de gracia de cuarenta dias. Una vez concluído ese margen de tiempo, el Santo Oficio iniciaba procesos contra quienes estaban considerados como falsos conversos, y de acuerdo al desarrollo del mismo, a la confesión del reo y a las delaciones de los testigos, se le sentenciaba de diversa manera.

Ya en 1485 se condena a Juan Gómez, bolsero, vecino de Ocaña. La actividad inquisitorial en esta villa fue continua pues solamente tres años después los inquisidores condenan a veintenueve personas, de las cuales diecisiete habían fallecido ya. La sentencia usual en estos casos obligaba a desenterrar los huesos y quemarlos, como se falla en el proceso contra Leonor Gómez, «[...] condenada por hereje y apóstata de la santa fe católica, seña de excomunión mayor, perdimiento y confiscación de todos sus bienes, que sus huesos sean quemados y sacados del lugar santo en el que están $[\ldots]{ }^{9}$.

En 1490, era condenado Ruy González, escribano, el más antiguo cristiano nuevo de la villa, que había muerto en 1473; en 1492 se condenaba a Blanca, la mujer de Sancho de Ribera, mientras que en 1494 eran relajados Diego Pérez y Diego Ramírez. Aparecen, aunque sin mencionar la fecha, los nombres de seis condenados más, que por los lazos de parentesco que les unen con otros de los condenados que acabamos de citar (esposos), situaríamos también en torno a estos años finales de siglo.

Muchos otros padecieron los rigores del procedimiento inquisitorial aunque su conclusión fuera más favorable, al no haber encontrado causas suficientes para condenarlos. Siguiendo la clasificación que plantea José Manuel Pérez-Prendes ${ }^{10}$, los sospechosos de herejía podían ser divididos en cuatro grupos: absueltos, abjurantes "de levi", "de vehementi» y

9 A.H.N. INQ. Leg. 152. Exp. 11

10 Pérez-Prendes, J.M: «El procedimiento inquisitorial», en Inquisición y conversos, Ill Curso de Cultura Hispano-judía y sefradí. Toledo. 1994. pág. 157. 
"de violenti», no incluyendo la denominación de «reconciliados», pues considera que es una valoración de la condición espiritual en la que se encuentran los no relajados. Según este autor, nadie que haya sido conocido jurisdiccionalmente por el Santo Oficio puede ser calificado de inocente, sino de no probado de culpabilidad. Además, sobre éstos, no se aplicaba el principio de "cosa juzgada», de tal modo que se les podía volver a procesar.

En 1490, eran absueltos Juan de la Fama, Gonzalo de León, Leonor Gómez y María Álvarez. En 1494, la Inquisición absolvía en Ocaña al bachiller Alonso González de Sevilla. Ya entrados en el siglo xv, en 1513 eran absueltos Ruy Díaz e Isabel de las Casas, ambos difuntos, y en 1535, era absuelto Alonso de León, del que se dice expresamente que era cristiano nuevo de judío. Se aportan también los nombres de otras cuatro personas indicadas como absueltas aunque desconocemos la fecha de su sentencia.

El grado de abjuración era proporcional al grado de sospecha de herejía. En 1490, abjuraba de levi, María de Ribera; mientras otros vecinos procesados de Ocaña, Alvaro de Ribera, carnicero, Alonso de Castro, borceguinero, Mencía Suárez, Francisca Ramírez y Catalina, la beata, fueron obligados a abjurar de vehementi, imponiéndoseles penas como «[...] acudir a misa con una vela encendida entre las manos [...]" "11, o penas más vejatorias tales como "[...] recibir cien azotes encima de un asno [...]" ${ }^{12}$.

Encontramos también casos de personas sobre las que se ha probado su delito de herejía y que, sin embargo, se retractan de su creencia, y a los que se les impone una penitencia canónica. Son los penitentes, como Fernando, hijo de Alonso González de la Cámara, y Fernando Nofre, zapatero, que fue penitenciado en 1529. En ocasiones el procedimiento o quedaba sin concluir o no se nos ha transmitido completo, como sucede en los procesos seguidos contra Alonso Núñez de Sevilla y su mujer, Catalina Gómez; y en el de Gonzalo Díaz, cirujano, y su mujer.

Aunque pertenecen al grupo de los que no han sido condenados, se menciona a cincuenta y cinco vecinos de Ocaña exclusivamente como reconciliados, ya fuera dentro del tiempo de gracia o no.

Para favorecer la integración en la vida común con los cristianos, tanto a los reconciliados cuanto a los hijos y nietos de condenados se les ofrecía la posibilidad ("habilidad") de volver a disponer de sus haciendas y poder desempeñar cargos públicos, administrativos o eclesiásticos, a cambio del

1 A.H.N. INQ. Leg. 158. Exp. 25.

12 A.H.N. INQ. Leg. 155. Exp. 16. 
pago de una elevada cantidad de dinero, que venía a corresponder al cinco por ciento de sus bienes.

Se ha conservado el registro de los habilitados para el arzobispado de Toledo, documento publicado por Francisco Cantera y Pilar León, Los judaizantes del arzobispado de Toledo en 1495 y 1497. El valor de las cantidades pagadas por cada vecino oscilaba de manera irregular entre los $100 \mathrm{mrs}$. y los $175.000 \mathrm{mrs}$. ya que era proporcional a la riqueza de los afectados, que eran, en su gran mayoría, artesanos que desempeñaban oficios variados como escribanos, plateros o sastres ${ }^{13}$.

Respecto a la villa de Ocaña, el documento establece una distinción entre los que fueron reconciliados por el Santo Oficio, y los hijos y nietos de reconciliados. Entre los primeros encontramos a 9 hombres y a 9 mujeres, cuatro de ellos matrimonios; mientras que en el segundo grupo aparecen 21 hombres y 23 mujeres, habiendo sólo tres casos de matrimonio. Además se menciona a siete hijos. En total, fueron habilitadas para la villa de Ocaña 69 personas en 1497.

Ya bien entrados en el siglo XVI encontramos un censo de todos los vecinos de Ocaña, convertidos, o descendientes de convertidos de judíos y de moros. Los vecinos están divididos en dos colaciones, la de Santa María y la de San Pedro, y suman un total de 213 personas, 6 de ellos moriscos, a las que habría que añadir algunas mujeres y niños que se mencionan junto al nombre de sus maridos. En bastantes ocasiones se indica el oficio desempeñado, en su gran mayoría artesanos, lo que es muy ilustrativo del sector económico en donde se insertaron los judeoconversos. Ya hemos mencionado cómo muchos judíos habían morado en la colación de Santa Maria, lugar en donde se mantiene poblamiento converso. Sin embargo, respecto al barrio de San Pedro, no gozamos de ninguna evidencia documental que atestigüe que contó con habitación hebrea.

\section{Parroquia de Santa María:}

1. Alcoçer Ricatón, que tiene tienda en la plaça, hijo de García de Toledo Ricatón, que vende en la plaça.

2. Antón Vázquez, hijo de Pero Núñez, moriscos. *

3. Alonso de Orgaz, herrero, y su mujer.

13 LEÓN TELLO, Pilar: «Los judios de Toledo en el último cuarto del siglo XV» en La expulsión de los judíos de España, II Curso de cultura hispano-judía y sefardí. Toledo. 1993. pág. 107. 
Parroquia de Sant Pedro:

4. Alonso Rodríguez, armero.

5. Alonso Pérez, hijo de Francisco Pérez de la Caxa.

6. Alonso Galán, e su mujer.

7. Alonso Galán, yerno de Juan Gutiérrez.

8. Alonso Gómez de la Hermosa.

9. Andrés Gómez, cortador.

10. Alonso Gómez, guantero.

11. Alonso Gómez, guantero, hijo de Pero Gómez Bitón.

12. Alonso de Çamora, escrivano.

13. Alonso de Castro, mesonero.

14. Alonso de Castro, sobrino de Gómez de Castro, joyero.

15. Alonso de Moya, cerero e guantero.

16. Alvaro de Alarcón, escrivano.

17. Antonio de Valladolid, platero.

18. Alvaro de Ribera, hijo de reconciliado.

19. Alvaro Gómez, hijo de Diego el Prieto.

20. Alonso Gómez, carpintero.

21. Andrés Gómez, cortador.

22. Alonso Gómez, hijo de Diego el Prieto.

23. Blas Gómez, hermano es de Juan Moreno, nietos de condenado.

24. Baltasar de Moya.

25. Bernaldino de la Cámara, hermano del dotor de la Cámara, e de Hernando de la Cámara.

26. Baltasar de Çamora.

27. Beatriz Alvarez, mujer de Pedro de Mora.

28. Castillo, çapatero.

29. Campos, sastre.

30. Cordova, sastre.

31. Cristóbal Pérez de Ocaña. 
32. Cristóbal Gutiérrez, boticario.

33. Cristóbal Gómez, çapatero.

34. Diego de Guzmán, convertido de judío, e su mujer también convertida de judía, hombre de más de ochenta años.

35. Diego Carrillo, sastre e su mujer, convertido de judío, hombre de más de setenta años.

36. Diego Vaca, e su mujer.

37. Diego Bezerro.

38. Diego Moreno.

39. Diego Gómez de la Hermosa.

40. Diego Rodríguez, espadero.

41. Diego Gómez Prieto.

42. Diego Pérez, hijo de Francisco Pérez de la Caxa.

43. Diego de Çamora, calcetero.

44. Diego Pérez, hermano de Cristóbal Pérez de Ocaña.

45. Diego de Mora, boticario.

46. Diego Roldán, calçetero.

47. Diego de Alarcón, mercader.

48. Diego Fernández, sombrerero.

49. Diego López de Torrijos, sastre.

50. El doctor Cámara.

51. El bachiller Azevedo, clérigo, hijo del dotor Agostín.

52. El doctor Luis Gutiérrez, su yerno.

53. Francisco Galván, çurrador, que se pasó a bevir a Yepes.

54. Francisco de Madrid, fiel de la carnicería convertido.

55. Francisco Ferrández.

56. Francisco Garcia, hermano de Juan García Bitón, clérigo.

57. Francisco de Vega, hermano de Pedro de Vega, calçetero.

58. Felipe de Godoy, hijo de Gonzalo de Godoy, moriscos. *

59. Fernando de Godoy, hermano del dicho Felipe.

60. Francisco Gómez, hermano del dicho Gonzalo de Godoy. 
61. Francisco Niñez, hijo de Pero Núñez Rubio.

62. Fernán Vázquez, hijo del dicho Pero Núñez Rubio.

63. Felipe de Santa Cruz, el viejo.

64. Felipe de Santa Cruz, el moço.

65. Fernando de Santa Cruz.

66. Francisco de Ungría, herrero, e su mujer.

67. Fernando Roiz, padre de Francisco de Ungría, este es hombre de 90 años.

68. Felipe Graviel.

69. Francisco Galán.

70. Francisco de Cespedes, prior.

71. Fernando de Villanueva, mercader.

72. Fernando Ramírez, escrivano.

73. Francisco de Moya.

74. Francisco de Medina, el viejo.

75. Francisco de Medina, su hijo, del dicho Francisco de Medina.

76. Fernando de la Cámara, hermano del dotor Cámara.

77. Francisco Galán, hijo de Pero Galán.

78. Francisco Rodríguez, armero.

79. Francisco Sánchez, tendero.

80. Fernan Galán, el viejo.

81. Francisco Pérez, odrero, convertido de judío.

82. Francisco Pareja Remendón e sus hijos.

83. Francisco Díaz, çirujano.

84. Francisco el Rubio, albardero.

85. Francisco de Segovia, sastre.

86. Francisco de Madrid, boticario.

87. Francisco Romero, escrivano de la audiencia secular.

88. Fernández, çirujano, hermano de Gómez Díaz, escrivano.

89. Francisco de Sevilla, sastre.

90. Fernando Galán, el moço, guantero. 
91. Francisco Caballero, trapero.

92. Fernán Ramírez.

93. Fernando del Rincón.

94. García de Toledo Recatón, que vende en la plaça, padre de Alcoçer Regatón.

95. García, tondidor a las puertas de las carnicerías.

96. Guillén Sánchez Galán, cortador de carne.

97. Graviel Fernández, çapatero.

98. Gonzalo de Godoy, y su mujer, moriscos convertidos de moros. *

99. Graviel de Santa Cruz.

100. Gaspar de Escalona.

101. Gaspar de Moya.

102. Gerónimo Díaz.

103. Gómez de la Cámara.

104. Graviel Gómez, guantero.

105. Gorje González.

106. Gómez de Castro, joyero.

107. Gómez Díaz, escrivano, hermano de Fernández çirujano.

108. Graviel Ferrández, yerno de Antonio de Valladolid, platero.

109. Gonzalo Gutiérrez, tintorero.

110. Juan de Yegros, confeso e hombre de ochenta años.

111. Juan Moreno, zapatero, nieto es de condenado.

112. Juan García Bitón, clérigo, alias Juan Gómez Bitón, clérigo.

113. Juan de Godoy, hijo de Gonzalo de Godoy, morisco. *

114. Juan de Villegas, hijo de María de Villegas.

115. Juan Vázquez, hijo de Pero Núñez Ruvio, moriscos. *

116. Juan Mancebo, sillero, y su mujer.

117. Juan Ysquierdo y Esperança, su mujer.

118. Juan Gómez, tendero, y su mujer.

119. Juan de la Lança.

120. Juan de Moya. 
121. Juan Gómez de Jaen.

122. Juan Cordero.

123. Jerónimo Díaz también se puso en la cuenta.

124. Juan Gutiérrez, guantero.

125. Juan Galán.

126. Juan López, çapatero.

127. Juan Gómez, yerno de Diego el Prieto.

128. Juan Pérez, odrero, hijo de convertido de judío.

129. Juan de Valençia, odrero.

130. Juan de Mora, hermano de Diego de Mora, boticario.

131. Juana Gómez, tendera.

132. Juan Núñez, çapatero.

133. Juan de Medina, el Rico.

134. Juan Ramírez, platero.

135. Juan Gómez Blanco, clérigo, este es hijo de Alonso Gómez Blanco procurador.

136. La de Pero de Yepes, biuda.

137. Leonor Gómez, hermana de Francisco Galván.

138. Lope de Castro e su mujer.

139. Lope Galán.

140. Lope de Ocaña, çapatero.

141. Leonor de Çamora.

142. María de Villegas, hermana del dicho Gonzalo de Godoy, moriscos. *

143. Micael de Orgaz, herrero.

144. Melchior de Moya.

145. Mari Gómez, hija de la del Valenciano.

146. Marcos Gómez.

147. Marcos Díaz de Navarra.

148. Miguel de Salamanca.

149. Navarro, çurrador.

150. Pedro de Ocaña, hijo de Juan de Ocaña, hijo de convertido de judío. 
151. Pedro de Vega, calçetero.

152. Pero Núñez Ruvio, e su mujer.

153. Pero Mexía herrero, e su mujer.

154. Pedro, herrero e calderero, e su mujer.

155. Pero Gómez, hijo de Juan Gómez, tendero. Casado.

156. Pero Ramírez, hermano de Fernán Ramírez.

157. Pero Rodríguez, armero.

158. Pero Gómez, nieto de Çellinos.

159. Pero Gutiérrez, tintorero.

160. Pedro Cordero.

161. Pedro de Ocaña.

162. Pero Gutiérrez.

163. Pero Galán, guantero.

164. Pero de Salamanca, odrero.

165. Pero Ramírez.

166. Peñalosa, el viejo, convertido de judío, e su mujer.

1£7. Pedro de Peñalosa, su hijo del dicho Peñalosa, odrero, el Pedro.

168. Pedro de Castro, hijo de la mesonera, madre de Alonso de Castro de condenado.

169. Pedro de Yepes, çapatero.

170. Pedro de la Torre, escrivano.

171. Pedro de Ocaña, çapatero.

172. Pero López Çiruelo, mercader, hijo de condenado.

173. Rodrigo de Çamora, calçetero.

174. Rodrigo de Carrión, e sus hijos.

175. Sant Martín, cortidor.

176. Sebastián Ferrández, hijo del mayordomo, convertido de judío, y hermano de los dichos Graviel Ferrández, e Francisco Ferrández.

177. Sebastián Merino.

178. Sebastián Gómez.

179. Sebastián Cordero, agujetero. 
180. Tomás Galán.

181. Un hijo de García de Toledo, suso dicho, que también vende en la plaça como el otro su hermano Alcoçer de condenado.

182. Una mujer de Salamanca, çapatero.

183. Una mujer de Francisco Gómez, çapatero.

184. Una mujer de Francisco Núñez, viuda, hermana de Villegas.

185. Una mujer, madre de Diego Vaca.

186. Una mujer, biuda, hermana de Diego Vaca, mujer que fue de Morales.

187. Una mujer de Pero López, sillero.

188. Una mujer de Francisco Mexía, y sus hijas.

189. Una mujer que se llama Beatriz Alvarez, mujer de Pero de Mora.

190. Unas dos hijas donzellas de Pero Núñez Ruvio.

191. Una mujer del merino, hija del dicho Juan Ysquierdo.

192. Una mujer de Francisco Mexía.

193. Unas hijas de Alonso Núñez de Sevilla.

194. Una biuda mujer de Pedro de Yepes.

195. Una mujer biuda que se dize la de Casarrubios.

196. Una mujer de Marcos Gómez.

197. Una mujer de Francisco Gómez.

198. Una mujer de Francisco Pérez de la Caxa.

199. Una mujer del Valençiano.

200. Una mujer de Juan Gómez. Prieto.

201. Una mujer que se llama la Bovadilla, convertida de judía.

202. Una mujer de Gonçalo Díaz.

203. Una mujer del bachiller de Ocaña.

204. Unas hijas de Fernán Galán.

205. Una mujer biuda que se llama la de Alonso de Frías.

206. Una mujer de Gonçalo de Frías, biuda.

207. Unas beatas de Villanueva.

208. Una mujer del doctor Agostín. 
209. Una mujer del doctor Suárez.

210. Una hija del doctor Suárez.

211. Una mujer de Juan López Çiruelo.

212. Una suegra de Antón Pérez.

213. Una madre de Juan Gómez Blanco, clérigo.

\section{Actividad económica}

La población judeoconversa de Ocaña desempeñó principalmente actividades propias del sector secundario, tal y como se desprende de la documentación inquisitorial. Entre los procesados por judaizantes en el Tribunal de Toledo se mencionan los oficios de tres de ellos: un borceguinero, un escribano y una mesonera. Además se alude a la profesión de los maridos de tres de las procesadas: la mujer de un zapatero, la mujer de un bolsero y la mujer de un cirujano.

La lista de habilitaciones de 1497 desvela más noticias acerca de la capacidad económica de los conversos pues implica la estimación de una cantidad variable que debían abonar en razón de su potencial económico. Para Ocaña el dinero pagado oscila entre los $100 \mathrm{mrs}$. de García de Ribera, hijo de Sancho de Ribera, y los 15.000 mrs. de Mençia Vasques, mujer de Gomes de la Camara. En total, los vecinos que compraron habilitación en Ocaña pagaron al Santo Oficio 74.600 maravedíes, con una media de 1.356 maravedíes por cada vecino habilitado. Media relativamente baja para el conjunto de las poblaciones del arzobispado de Toledo, lo que indica una escasa potencilidad económica de los conversos habilitados de Ocaña frente a la riqueza de otros cristianos nuevos que recibieron habilitación.

En algunos casos se hace referencia a su oficio. Así, siete guanteros, dos escribanos, un zahonero, un sastre, un platero, un notario, un zapatero y un calcetero, aparecen entre aquellos que recibieron habilitación de la Inquisición.

Esta característica se mantendrá aún en 1537. De los 175 hombres que se registran en el censo de cristianos nuevos de judío o de moro realizado para la villa de Ocaña se ha descrito la actividad profesional de 92 de ellos, lo que supone que conocemos la ocupación de más del cincuenta por ciento de la población conversa. Hay nueve zapateros, ocho tenderos, siete guanteros, seis escribanos, seis sastres, cinco calceteros, cinco odreros, cuatro herreros, cuatro boticarios, cuatro clérigos, tres mercaderes, tres armeros, tres plateros, 
dos cortadores, dos joyeros, dos doctores, dos zurradores, dos carniceros, dos cirujanos, dos tintoreros, un mesonero, un cerero, un carpintero, un espadero, un sombrerero, un prior, un albardero, un trapero, un sillero, un cortidor y un agujetero.

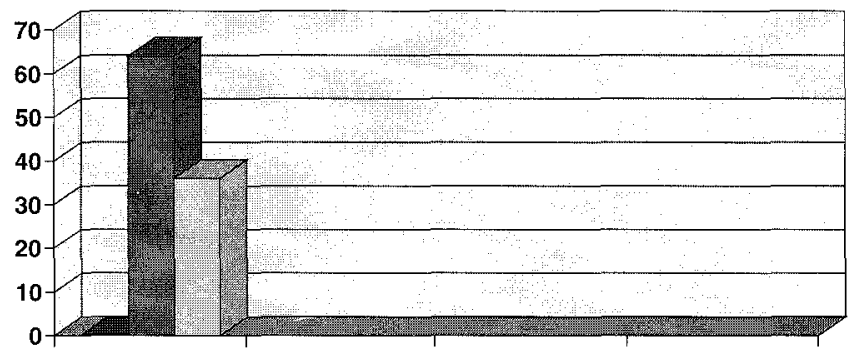

\section{La religiosidad de los judeoconversos}

La Inquisición vivía de evidencias. Era necesario demostrar un comportamiento desviado de la ortodoxia cristiana para poder condenar a cualquier procesado. De ahí que los procesos inquisitoriales contra judaizantes centren toda su atención en aquellas manifestaciones de religiosidad externa que dejen al descubierto prácticas o costumbres mosaicas. No se reparaba en la devoción interna o en la intimidad de la fe ${ }^{14}$.

Así pues, los datos que nos proporcionan aluden a aquellos actos que eran objetivables desde fuera, gracias, en gran medida, a los testimonios y delaciones de aquellos que vieron realizar tal o cual práctica. Acudir al oficio sinagogal, principalmente el Shabat, era muestra irrefutable de judaísmo. A Leonor Gómez, difunta, los inquisidores la acusan, entre otras cosas, de «[...] acudir muchas veces a la sinagoga a oir las oraciones de los judios, especialmente el sábado, e el lunes e el jueves, e se asentaba entre los judíos e allí oía sus oraciones como propia judía e se alababa muchas veces[... ${ }^{15}$ ".

Alhojar, mujer de León Daça, testificó contra ella afirmando que iba a la

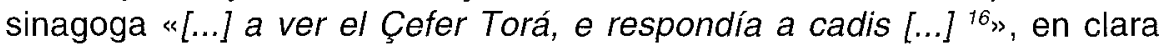

\footnotetext{
14 RÁBADE OBRADÓ, M. ${ }^{a}$ Pilar: «Religiosidad y práctica religiosa entre los conversos castellanos (1483-1507)», en BRAH, CXCIV, (enero-abril, 1997). pág. 99.

15 A.H.N. INQ. Leg. 152. Exp. 11.

$16 \quad$ A.H.N. INQ. Leg. 152. Exp. 11.
} 
alusión a la veneración de los rollos de la Ley, y la recitación del qadish, plegaria de origen arameo con la que concluyen todos los oficios diarios en la sinagoga mediante la cual se implora la venida del Reino de Dios y que precisa de minyán ${ }^{17}$. Sin embargo, otros testigos como Pero Gómez Blanco o Clara, mujer de Ysaque, desvelan en su declaración un intento de ocultar en cierto modo esta práctica pues afirman que Leonor Gómez le dijo al primero "[...] que las camas que había fecho a las espaldas de su casa que vernían a la puerta de la xinoga, que las fiso por estar allí las pascuas e otros días a oír las oraciones de la xinoga [...], y acudía a casa de la segunda, situada junto a la sinagoga, "[...] los lunes e jueves e se ponía a una ventana por do se parescía la xinoga e oía desde allí las oraciones del rabí, quando sacavan la Torá se umillaba e lloraba [...]" ${ }^{18}$.

Ruy González, escribano, «[...] guardaba la ley de Moisés yendo a la sinagoga a oir oraciones judaicas e las oía juntamente con los judíos $[\ldots]^{19}$, o Ruy Díaz, del que se nos dice sucintamente que «[...] iba a la xinoga [...]» 20.

La lengua oficial de la liturgia era siempre el hebreo, aunque en ocasiones se utilizara el arameo, lengua común de los semitas en los primeros siglos después de Jesucristo ${ }^{21}$. Así, Pedro de Madrano, testigo en el proceso seguido contra el escribano Ruy González, atestigua que "[...] resaba muchas veces en ebraico e díxole porque rezas en ebraico e respondió e dixo todos los salmos son unos salmos que es más devoto en ebraico [...]” ${ }^{22}$.

El cumplimiento del Shabat o descanso es otro precepto obligado por la ley mosaica. Exigía una supresión total de trabajos y esfuerzos, y era un día dedicado por entero a la oración y a la profundización en el conocimiento de Adonay. Elvira López, mujer de Maestre Lope, cirujano, "[...] guardó los sábados por honra y observancia de la Ley de Moisés [...]" ${ }^{23}$, y de María de Ribera, mesonera, se nos dice que «[...] holgó los sábados $[\ldots.]{ }^{24}$. Alonso de Castro, "[...] por honra y observancia del sábado se excusaba en ellos de hacer las obras serviles como en los otros días entre semana $[\ldots], 25$.

\footnotetext{
Cantera Montenegro, Enrique: Aspectos de la vida cotidiana de los judíos en la España Medieval. Madrid. 1998. pág. 21.

18 A.H.N. INQ. Leg. 152. Exp. 11.

19 A.H.N. INQ. Leg. 155. Exp. 16.

$20 \quad$ A.H.N. INQ. Leg. 143. Exp. 19

CANTERA,E: Op. cit. pág. 22.

A.H.N. INQ. Leg. 155. Exp. 16.

A.H.N. INQ. Leg 160. Exp. 13.

A.H.N. INQ. Leg. 176. Exp. 6.

5 A.H.N. INQ. Leg. 139. Exp. 4.
} 
Este sencillo precepto se fue adornando con diversas prácticas y ritos más propios de la tradición y la costumbre que de la devoción, y que sin embargo, fueron asociados por los inquisidores como ejemplo y expresión de herejía judaica.

El calendario lunar por el que se rigen los semitas hacía comenzar el sábado con la puesta de sol del viernes. La imposibilidad de hacer cualquier esfuerzo precisaba de una organización previa. Había que cambiarse de ropa, cocinar y encender fuego antes de que se metiera el sol. De ahí que quien dispusiera su actividad de esta manera sería tachado irremediablemente de criptojudío.

Habían de encenderse por lo menos dos candiles limpios que arderían ininterrumpidamente durante la jornada de descanso. Esta práctica fue muy frecuente entre los judaizantes españoles. En Ocaña, María Alvarez, "[...] encendía candiles limpios los viernes en la noche [...]" ${ }^{26}$, y María de Ribera es acusada de «[...] encender candiles limpios los viernes en las tardes más temprano que otros días [... " ${ }^{27}$. En la testificación de Doña Lucía, mujer de Fernando Alonso Malsepica, contra Elvira López se afirma que «[...] encendía candiles muchos los viernes en las noches e holgaba aquella noche e los sábados [...] ${ }^{28}$.

Para la cultura hebrea la limpieza va íntimamente ligada a la práctica religiosa. En una época donde la higiene era tan escasa, aparecer limpio ante Dios y ante los correligionarios era una manera externa de manifestar la purificación del sábado. Aunque no estaba incluída por la tradición en los deberes sábaticos, la muda de ropa, especialmente de la camisa, se convirtió en uso frecuente por parte de la población judía. En los procesos contra judaizantes de Ocaña solamente se hace referencia a este uso en el seguido entre 1487 y 1490 contra María de Ribera, pues se declara como delito el «[...] holgar los sábados y ataviarse en ellos [...]»"29.

También afectaba la religiosidad judía a los hábitos alimenticios. Al no poderse cocinar durante el Shabat, desde el viernes a mediodía preparaban un potaje conocido como adafina, compuesto de carne, garbanzos, $y$ un variado grupo de legumbres y verduras, que se colocaba en un horno para que se mantuviera caliente ${ }^{30}$. De Alfonso Núñez de Sevilla se decía que «[...] fablando con otros comentaba que no le quitarian de comer en la

\footnotetext{
A.H.N. INQ. Leg. 134. Exp. 2.

A.H.N. INQ. Leg. 176. Exp. 6.

A.H.N. INQ. Leg. 160. Exp. 13.

A.H.N. INQ. Leg. 176. Exp. 6.

Cantera, E: Op. cit. pág. 25.
} 
semana un día o dos como los judíos comen e de su carnicería por todo el mundo, el cual tenía quien lo sabia bien guisar por ser fecho guisado con cerimonia judaica, e por mejor lo cumplir ( la ley de Moisés), se juntaba con otros herejes a comer adafinas en los sábados por ser guisadas el día antes $[\ldots] \geqslant 31$.

A Alonso de Castro, borceguinero, procesado entre 1498 y 1499, la Inquisición lo presenta como judeoconverso pues eritre otras faltas «[...] por honra y observancia de la ley de Moisés, en los sábados comía viandas e manjares de los judíos e con ellos, e de sus adafinas por ser fecho e guisado con cerimonia judaica e del día antes [...]" 32 .

Según nos expone detalladamente Enrique Cantera en su libro ya citado, era usual entre los semitas que después del oficio de la tarde del viernes se reuniera la familia judía en torno a una mesa donde estaban colocados una copa de vino y dos panes, simbolizando el maná recibido por los israelitas en su travesía por el desierto. El padre tomando la copa en las manos recitaba el qiddush, agradeciendo a Dios el sábado y el fruto de la vid, dando posteriormente de beber a los comensales ${ }^{33}$. A Leonor Gómez la acusa Catalina la Tella de "[...] estando cenando una noche tomó un vaso con un poco de vino e rezó sobre él ciertas palabras que este testigo no las entendió, e bevía ella un poco e dio a su marido e a sus hijas dello [...]". Esta información se ve corroborada con la testificación que hizo Teresa Díaz, mujer de Juan de Castronuño, quien asegura que "[...] en fin de la cena tomaron un vaso de vino en la mano e resaron sobre él, e bebieron a sorbillos de aquel vino [...]" ${ }^{34}$.

Las prescripciones alimentarias del judaísmo son muy estrictas y están sujetas a un ritual específico, que exige que el animal, que debe estar sano, haya sido matado con un cuchillo sin mella. Esta circunstancia necesitaba de una carnicería propia de los judíos, donde éstos pudieran adquirir sus productos sin faltar a lo dispuesto por la tradición. Ruy Díaz, procesado durante 1511 y 1512 , es inculpado de haber «[...] comido carne judía, comprada en la carnicería de los judíos [...73 ${ }^{35}$. Existe también un conjunto de alimentos vedados como el cerdo, el conejo, la liebre o pescados sin escamas. Esta restricción no era cumplida con severidad por los conversos, quienes se limitaban en gran medida a no ingerir productos

\footnotetext{
A.H.N. INQ. Leg. 168. Exp. 8.

A.H.N. INQ. Leg. 139. Exp. 4.

CANTERA, E: Op. cit. pág. 25.

A.H.N. INQ. Leg. 152. Exp. 11.

A.H.N. INQ. Leg. 143. Exp. 19.
} 
del cerdo ${ }^{36}$, como le ocurría a María Alvarez a quien se la acusa de no comer tocino ${ }^{37}$.

Muchos conversos procesados debieron responder al hecho de si purgaban la carne eliminando de la pierna del cordero el nervio ciático o «landrezilla», en memoria de la lucha de Jacob con el ángel. A Alfonso Núñez de Sevilla, los inquisidores le imputan el delito de que «[...] traía carne para comer de la carnicería de los judíos por ser muerta con cerimonia judaica, e cuando le daban carne de la pierna donde estaba la landrezilla no lo quería e decía a los judíos que bien sabía que él no lo comía aquello por tener la guilad nase ( gid hanashed= nervio oculto) por cumplir la cerimonia judaica porque no oviese de purgar la carne [...]" ${ }^{38}$, y a María Alvarez, mujer de Luis González de la Hoz, quien "[...] en muchas ocasiones e de continuo por guarda de la ley de Moisés purgó la carne muy por menudo e depiscandola como los judíos lo purgan, e así mismo hendía la pierna e sacaba la landrezilla muchas veces [...]" ${ }^{39}$.

En el marco de las prescripciones alimentarias se encuadra también la práctica del ayuno. Los judíos celebraban ayunos en las festividades más importantes de su calendario como durante la Pesah o Pascua, o el Yom Kippur, día de la expiación. Esta costumbre está también muy arraigada entre los cristianos, especialmente durante la cuaresma. No era infrecuente escuchar denuncias contra judaizantes a quienes se les acusaba de no respetar lo dispuesto por la Iglesia. Alonso de Castro cuenta entre sus delitos como judaizante el haber "[...] quebrantado los domingos e fiestas de la madre Santa Iglesia e comía carne en cuaresma y los días vedados por la Santa Iglesia [...]” ${ }^{40}$.

El ayuno más significativo para los hebreos era el que tenía lugar durante la celebración del Yom Kippur, el día del Perdón, y denominado en las fuentes cristianas «Ayuno Mayor de los judíos». Esta fiesta pone fin a diez días de penitencia con que comienza el nuevo año para los judíos y es una muestra más de sometimiento y humildad para con Yahvé. El ayuno era absolutamente riguroso. Una testigo contra Leonor Gómez prueba que la acusada era judaizante aseverando que "[...] un día del ayuno mayor que folgaba aquel día e ayunó e estaba oyendo las oraciones de los judíos [...]" ${ }^{41}$.

3o RÁbADE ObaAdó, M. ${ }^{a}$ Pilar: «Religiosidad y práctica religiosa entre los conversos castellanos (1483-1507)» en BRAH, CXCIV, ( Enero-abril 1997 ). pág. 113.

A.H.N. INQ. Leg. 134. Exp. 2.

A.H.N. INQ. Leg. 168. Exp. 6.

A.H.N. INQ. Leg. 134. Exp. 2.

A.H.N. INQ. Leg. 139. Exp. 4.

A.H.N. INQ. Leg. 152. Exp. 11. 
Acusación que repite otra testigo en el proceso contra Blanca Díaz pues se insiste en que «[...] la mujer de Gómez, que tiene unos hijos que se llaman los de Castro que ayunava el ayuno mayor [...]" ${ }^{42}$.

En la Pascua conmemoran los hebreos la liberación de la esclavitud de Egipto. Muchas y muy variadas son las exigencias que la religión mosaica impone para estos días. Sin embargo, hay una en la que las fuentes cristianas inciden sobre las demás. Era respecto al consumo de pan sin fermentar o «pan cenceño», obligación estricta que debían respetar los judíos a lo largo de los ocho días que duraba esta celebración. A María de Ribera, mesonera, se le imputaba el delito de haber «[...] comido el pan cenceño en los tiempos que los judíos lo comen [...]" "43. Resulta curioso el caso de Blanca Díaz quien justificaba ante la Inquisición el consumo de pan ácimo «[...] porque estaba con dolores [...]" ${ }^{44}$, lo que evidencia que muchas prácticas propias de la vida cotidiana podían hacer pasar a un cristiano por judío o viceversa.

De carácter más festivo es el Sukkot o fiesta de los Tabernáculos en agradecimiento a Dios por la protección dispensada durante el Éxodo. Los documentos inquisitoriales la mencionan como «Pascua de las Cabañuelas", ya que lo que solía hacerse eran una especie de chozas o cabañas de ramas en las calles, plazas o patios de las juderías, donde se vivía y comía en el tiempo que duraba la conmemoración. A los ojos de los convecinos cristianos debía ser una fiesta curiosa y extraña, cuyo cumplimiento no dejan de denunciar. Así, Ruy González, escribano, es acusado de «[...] entrar en las cabañuelas e comer e beber en ellas de las viandas e guisados de los judíos [...]" ${ }^{45}$.

Aunque la religión judía no se caracteriza por un pietismo exagerado, sí que eran corrientes ciertas manifestaciones de caridad, como dar limosna a judíos necesitados, o contribuir con los gastos de la sinagoga, fundamentalmente con la compra o donación de aceite para la lámpara que luce en la misma. Abraem Baquis, encargado de recoger dicho aceite testifica contra María de Ribera, diciendo que la acusada «[...] daba a este testigo cada viernes çedaca para azeite a la xinoga [...]" ${ }^{46}$, y contra María Alvarez pues «[...] le dio dos jarros de aceite para la sinagoga [...]" ${ }^{4}$.

\footnotetext{
42 A.H.N. INQ. Leg. 141. Exp. 15.

A.H.N. INQ. Leg. 176. Exp. 6.

A.H.N. INQ. Leg. 141. Exp. 13.

A.H.N. INQ. Leg. 155. Exp. 16.

A.H.N. INQ. Leg. 176. Exp. 6.

47 A.H.N. INQ. Leg. 134. Exp. 2.
} 
Si bien todas estas menciones aluden a aspectos de carácter general puestos en práctica muy frecuentemente por los judeoconversos, en ocasiones la finura de lo expuesto en los procesos nos concede detalles curiosísimos que entran ya casi en el terreno de la superstición. Es el caso de Ruy González, a quien un testigo denucia por que se cortaba las uñas al modo judaico, exponiendo que «[...] le vido que cuando se cortaba las uñas ponía la halda en que callese e cogialas e ponialas en un agujero e echábalas un poco de tierra encima [...]" ${ }^{48}$. No era para menos la angustia y el terror que la Inquisición provocaría entre los falsos convertidos si llegaba a juzgar hasta este extremo.

\section{CONCLUSIÓN}

Reconquistada por Alfonso VI, Ocaña no estuvo definitivamente en manos cristianas hasta el reino de Alfonso VII quien la recuperó de los almorávides, y la organizó concediéndole fuero. Desde fines del siglo XIII conocemos la existencia de una aljama de judíos que a lo largo de los siglos medievales fue aumentando demográfica y económicamente, hasta llegar a ser a fines del siglo Xv la tercera comunidad que más contribuyera en los repartimientos de los castellanos de oro, alcanzando una población de más de mil quinientas personas.

Aunque según hemos visto el fenómeno converso está documentado en Ocaña desde los tiempos del apostolado de San Vicente Ferrer, principalmente entre 1407 y $1412^{49}$, el "problema converso» no adquiere importancia hasta el establecimiento del Tribunal del Santo Oficio en Toledo en mayo de 1485.

Ahora bien, si es cierto que de acuerdo a las contribuciones económicas con que tributaba la aljama se observa una reducción en el importe de más del $30 \%$ entre 1485 y 1489 , lo que pudo estar motivado por un aumento considerable de bautismos, no es menos evidente que de las 34 personas que la Inquisición relajó al brazo secular durante los últimos años del siglo xv muchos habían fallecido ya, demostrando que bastantes cristianos nuevos de judío mantuvieron su credo a lo largo de la segunda mitad del siglo XV.

Los casos de procesados fueron aún más numerosos, existiendo cincuenta y cinco vecinos que fueron reconciliados, otros dos vecinos que

$48 \quad$ A.H.N. INQ. Leg. 155. Exp. 16.

49 PÉREZ, J: Historia de una tragedia. La expulsión de los judíos de España. Barcelona. 1993. pág. 61. 
fueron penitenciados, cuatro obligados a abjurar de vehementi y dos de levi. Hubo ocho procesados, entre 1490 y 1535, contra los que no se probó su culpa y debieron ser absueltos.

En 1497 la Inquisición permitía a sesenta y nueve vecinos de Ocaña, condenados o descendientes de condenados, desempeñar oficios públicos y dignidades eclesiásticas gracias a la compra de habilitación por un montante total de 74.600 maravedíes. Cantidad ésta muy por debajo de las que se pagaron en Almagro, Almodóvar del Campo, Alcazar de Consuegra, Alcalá de Henares, Torrijos o Talavera ${ }^{50}$.

Exceptuando a Mencía Vazquez y a Mari Núñez, que contribuyeron con 15.000 y $9.000 \mathrm{mrs}$. respectivamente, el potencial económico de los vecinos habilitados de Ocaña es bastante inferior, contando con capitales medios en torno a los cincuenta o sesenta mil maravedíes de renta al año, quedando patente una considerable disyuntiva económica pues un reducido grupo de judeoconversos adinerados $(3,6 \%)$ acumulaba casi un tercio de toda la riqueza. Esta tendencia fue semejante en la gran mayoría de las localidades del arzobispado de Toledo, en donde una pequeña élite trató de mantener unidos sus lazos familiares y de parentesco para conservar sus niveles de fortuna.

No obstante, las diferencias económicas no son exageradas ya que el grueso general de la población judeoconversa se dedicó al sector secundario, siendo fundamentalmente artesanos, ¿consecuencia de su pasado judío?, lo que implicaba una mayor homogeneización social.

En el censo de 1537 no se indica ninguna cantidad económica. Tan sólo se observa el mantenimiento de oficios artesanales de muy diversa índole, a la vez que aumentan las actividades propias del sector terciario, debido probablemente a una mayor participación de los conversos en la vida concejil, y una mejor integración en el seno de la sociedad cristiana. Llama la atención que no se haga mención a ningún judeoconverso como trabajador del campo o ganadero.

La documentación inquisitorial revela una sociedad judeoconversa en Ocaña poco disgregada por la presión de la Inquisición o por las exigencias de la expulsión. Entre los primeros condenados o reconciliados abundan los matrimonios, dando muestras de gran cohesión ya que la célula fundamental de la sociedad, la familia, se mantenía junta. Esta característica perdura en 1537, pues entre los 213 nombres de convertidos de judíos o de moros hallamos claras relaciones de parentesco.

50 CARRASco, R: "Solidaridades judeoconversas y Sociedad local» en Inquisición y conversos, III curso de cultura hispano-judía y sefardi. Toledo. 1994. pág. 72. 
Así, además de los catorce matrimonios de judeoconversos mencionados, aparecen hermanos como los Vega, los Mora, los Recatón, los Cámara, los Castro o linajes como los Ramírez, los Çiruelo o los Gómez Blanco. Esta característica es aún más plausible entre los conversos de moro, pues se articulan en dos familias, los Núñez Rubio y los Villegas.

No debemos olvidar también, que muchos de los registrados como cristianos nuevos de judío en 1537 son hijos y/o nietos de condenados o reconciliados. Aunque muchos judeoconversos mantuvieron veladamente la fe mosaica, a lo largo del siglo xv las fuentes documentales ponen de manifiesto un intento de mayor integración en la sociedad mayoritaria cristiana por parte de la población conversa.

Disminuyen considerablemente los condenados y reconciliados lo que evidencia un aumento de las conversiones sinceras. Además, muchos judeoconversos desempeñan cargos y dignidades relevantes, pues encontramos varios escribanos, cuatro clérigos y un prior. En otros casos, se intentará borrar el pasado mediante alianzas matrimoniales con la nobleza urbana. Así, el bachiller Alonso González de Sevilla, hijo de conversa y absuelto por la Inquisición en 1494, se casó con una cristiana vieja e hijadalgo. De este enlace nació un hijo, llamado Salazar, que entonces desempeñaba el cargo de alcalde en Ocaña ${ }^{51}$.

En definitiva, encontramos en Ocaña una numerosa población judeoconversa que trabaja casi exclusivamente en actividades artesanales, lo que les permite gozar de una economía saneada aunque no boyante, donde los lazos de parentesco se han mantenido firmes, y que buscó paulatinamente acallar las voces del pasado participando activamente en la vida concejil. 